\title{
Patient cumulative radiation exposure in interventional cardiology
}

\author{
M.-O. BERNIER ${ }^{1}$, S. JACOB ${ }^{1}$, C. MACCIA ${ }^{2}$, O. BAR ${ }^{3}$, O. CATELINOIS ${ }^{4}$, \\ D. BLANCHARD ${ }^{3}$, D. LAURIER ${ }^{1}$
}

(Manuscript received 8 August 2011, accepted 14 November 2011)

ABSTRACT Interventional cardiology procedures can involve potentially high doses of radiation to the patients. Stochastic effects of ionising radiation - radiation-induced cancers in the long term - may occur. We analysed clinical characteristics and dosimetric data in a population of patients undergoing interventional cardiology. In all, 1591 patients who had undergone coronarography and/or angioplasty in the course of a year at the Saint-Gatien Clinic in Tours (France) were included. Information on patients' individual clinical characteristics and Dose-Area Product values were collected. Organ doses to the lung, oesophagus, bone marrow and breast were mathematically evaluated. The median age of patients was 70 years. Their median cumulative dosearea product value was $48.4 \mathrm{~Gy} . \mathrm{cm}^{2}$ for the whole year and the median effective dose was $9.7 \mathrm{mSv}$. The median organ doses were $41 \mathrm{mGy}$ for the lung, $31 \mathrm{mGy}$ for the oesophagus, $10 \mathrm{mGy}$ for the bone marrow and $4 \mathrm{mGy}$ for the breast. Levels of doses close to the heart appear to be rather high in the case of repeated interventional cardiology procedures. Clinical characteristics should be taken into account when planning epidemiological studies on potential radiation-induced cancers.

Keywords: Interventional cardiology / exposure to ionising radiation / patients / epidemiology / dosimetry

RÉSUMÉ Exposition cumulée aux rayonnements ionisants des patients en cardiologie interventionnelle : caractéristiques cliniques et dosimétriques.

Les procédures de cardiologie interventionnelle entraînent une irradiation des patients susceptible d'engendrer des effets stochastiques à long terme tels que les cancers radio-induits. L'objectif était de caractériser la population exposée en termes de doses d'irradiation cumulées. Ont été inclus 1591 patients, soumis à au moins une coronarographie ou une angioplastie sur une année dans un service d'hémodynamique de la clinique St-Gatien à Tours (France). Des informations cliniques et dosimétriques ont été collectées. Les doses ont été mathématiquement estimées pour le poumon, l'œsophage, la moelle osseuse et le sein. L'âge médian des patients était de 70 ans. Le pourcentage de co-morbidités était plus élevé que dans la population générale. La médiane cumulée sur l'année de leur produit dose surface et de leur dose efficace était respectivement de $48,4 \mathrm{~Gy} . \mathrm{cm}^{2}$ et de $9,7 \mathrm{mSv}$. Les médianes des doses équivalentes cumulées à l'organe étaient de $41 \mathrm{mGy}$ pour le poumon, $31 \mathrm{mGy}$ pour l'œsophage, $10 \mathrm{mGy}$ pour la moelle osseuse et $4 \mathrm{mGy}$ pour le sein. Les niveaux de doses reçus au niveau des organes proches du cour lors d'actes répétés

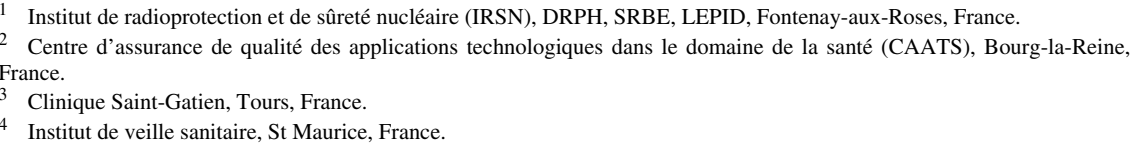


de cardiologie interventionnelle sont relativement élevés. Le suivi épidémiologique de cette population à long terme nécessite de prendre en compte les caractéristiques cliniques de ces patients.

\section{Background}

Interventional cardiology (IC) is a minimally invasive technique aiming to diagnose and/or possibly treat coronary artery stenosis. An IC procedure (ICP) requires the use of $\mathrm{X}$-rays to imaging heart vessels and involves prolonged fluoroscopy times as well as the acquisition of a large number of radiographic runs. The frequency of this radiological procedure has substantially increased over the past few years (Le Tourneau et al., 2002) in the vast majority of the industrialised countries. Despite the clear clinical benefit to the patient, an ICP may lead to a rather high dose of ionizing radiation, both to skin level and to organs surrounding the heart. Radiation dose levels greater than 2 Gy have been described in the literature (Faulkner and Vano, 2001) as producing deterministic effects such as skin injuries to patients (Vano et al., 2001) while long-term effects such as cancer have been discussed for lower doses of ionizing radiation by several authors (Boice et al., 1991; Howe, 1995; Meinert et al., 1999; Doody et al., 2000; InfanteRivard et al., 2000; Preston et al., 2003; Preston et al., 2007). Despite the relatively low level of effective doses associated to ICP, rather high doses to organs surrounding the heart have been reported (Pattee et al., 1993; Harrison et al., 1998; Delichas et al., 2003). Hence, the relevance of setting up epidemiological studies on cancer risks assessment associated with exposure during ICP for specific cancer location (Malisan et al., 2008) was underlined. Within the framework of paediatric cardiology two epidemiological studies (McLaughlin et al., 1993; Modan et al., 2000) have already evaluated the risk of cancer following cardiac catheterization in childhood, with conflicting results. In the specific area of IC only one epidemiological study dealing with these risks has focused on adult patients undergoing ICP (Lambe et al. 2005). The scope of the study - which observed no excess of cancer risk - was limited by the short median follow-up $(<5$ years) and the lack of estimation of the received doses. However, setting up such a study with a prolonged follow-up and an appropriate dosimetric evaluation of the patients' exposure would require a better description of the clinical and dosimetric outcomes of the target population.

The objective of the present paper was to characterize clinical features and dosimetric data of adult patients who underwent ICP in order to document the feasibility of an epidemiological study. 


\section{Methods}

A population of 1591 patients having undergone in 2005 at the Saint-Gatien Clinic in Tours (France) form 1 to 5 IC coronary angiography (CA) and/or percutaneous transluminal coronary angioplasty (PTCA) was included in this study. To those patients corresponded 2095 ICP which were performed by three different operators on a Philips Medical System "Integris Allura 9C" X-ray equipment. This latter was equipped with a transmission chamber installed at the X-ray tube housing, which enabled measurements of the corresponding Dose area product (DAP) values. For each procedure, the following clinical and technical data were electronically and prospectively recorded through the software "CARDIOREPORT": date and type of procedure, operator code, patient characteristics (date of birth, medical history, previous cardiac by-pass and/or stenting, smoking habits, size and weight) and total cumulative DAP value.

\subsection{Dosimetric evaluation}

Various dosimetric parameters were either assessed or recorded during both fluoroscopy mode and radiographic acquisitions: the DAP value, the effective dose and the absorbed organ dose. The dosimetric approach used to calculate organ doses around the heart used the PCXMC software, developed and validated within the frame of an EU project (Tapiovaara et al., 1997). This sofware uses the Monte Carlo method to simulate the phenomenon of energy deposit linked to interactions between photons incidents and the biological environment using a phantom with the same morphological characteristics as the patient. The approach was validated on a sample of 177 patients from the St-Gatien Clinic whose detailed dosimetric data were available (Journy et al., 2011). For a given organ a dosimetric factor (DF) was estimated, taking into account the type of procedure (CA or PTCA) and the operator. Finally, for each of the 2095 examinations considered in the current study, organ doses to the lung, bone marrow, oesophagus and breast were estimated by multiplying the corresponding DF with the DAP.

For patients who had undergone several procedures during the year, the cumulative DAP, effective dose and organ doses were calculated by summing the corresponding dose values of each examination.

\subsection{Statistical analyses}

Due to the asymmetrical distribution of both clinical and dosimetric variables, summary statistics are expressed in terms of median value. Depending on their qualitative or quantitative definition, clinical and dosimetric data were compared using Chi-square or Wilcoxon tests, respectively. All analyses were performed with the SAS software, version 8. 
TABLE I

Patients' clinical characteristics.

\begin{tabular}{|c|c|c|c|c|}
\hline & $\begin{array}{c}\text { Total } \\
(\mathrm{N}=1,591)\end{array}$ & $\begin{array}{c}\text { Men } \\
(\mathrm{N}=1,181)\end{array}$ & $\begin{array}{c}\text { Women } \\
(\mathrm{N}=410)\end{array}$ & $\mathrm{p}$ \\
\hline Age at first examination (years)* & $70(30-93)$ & $69(31-91)$ & $73(30-93)$ & $<0.001$ \\
\hline Body mass index $\left[\mathrm{kg} \cdot \mathrm{m}^{-2}\right]^{*}$ & $27(16-61)$ & $27(16-61)$ & $26(17-50)$ & $<0.01$ \\
\hline Current or former smokers ${ }^{\dagger}$ & $510(33 \%)$ & $444(39 \%)$ & $66(17 \%)$ & $<0.001$ \\
\hline Family history of coronary heart disease ${ }^{\dagger}$ & $590(38 \%)$ & $422(37 \%)$ & $168(42 \%)$ & 0.08 \\
\hline Diabetes $^{\dagger}$ & $391(25 \%)$ & $289(25 \%)$ & $102(25 \%)$ & 0.89 \\
\hline Hypertension $^{\dagger}$ & $991(63 \%)$ & $702(60 \%)$ & $289(71 \%)$ & $<0.001$ \\
\hline Hypercholesterolemia $^{\dagger}$ & $956(61 \%)$ & $719(62 \%)$ & $237(58 \%)$ & 0.31 \\
\hline History of myocardial infarction ${ }^{\dagger}$ & $214(14 \%)$ & $177(15 \%)$ & $37(9 \%)$ & $<0.01$ \\
\hline History of coronary bypass ${ }^{\dagger}$ & $165(11 \%)$ & $151(13 \%)$ & $14(3 \%)$ & $<0.001$ \\
\hline
\end{tabular}

Median (min-max)

Missing data: smoking: 64; family history of coronary heart disease: 51; diabetes: 18; hypertension: 15 ; hypercholesterolemia: 32; history of myocardial infarction: 27 ; history of coronary bypass: 25 .

\section{Results}

\subsection{Description of patients' clinical variables}

Out of the 1591 patients included in the study, 74\% were men. As shown in Table I, their median age at first examination was 70 years, with a higher proportion of patients under 60 years among men (28\%) rather than women (15\%). Approximately one third of the patients were a smoker or former smoker, with a higher percentage among patients younger than 60 years old (64\% and 50\% among men and women, respectively). Diseases associated with atherosclerosis varied for both sexes from $11 \%$ to $63 \%$ with a significant increased percentage of hypertension for women and a significant increased percentage of previous myocardial infarction and coronary bypass for men.

\subsection{Description of patients' dosimetric variables}

Two thousand and ninety five ICP were carried out in 2005 with an average value of 1.3 examinations per patient $(\min 1, \max 5) .73 \%$ of the patients underwent one single procedure, $23 \%$ two procedures and $4 \%$ more than 2 procedures. The CAs and PTCAs accounted for $59 \%$ and $41 \%$ of all procedures, respectively. The highest values of DAP were observed for PTCAs with a median value of 50.7 (min-max, 1.5-587) compared to CA median value of 36.2 (min-max, 1.6-335.7). 
TABLE II

Characteristics of patients' cumulative dosimetry.

\begin{tabular}{|lcccc}
\hline & 1st quartile & $\begin{array}{c}\text { 2nd quartile } \\
\text { (median) }\end{array}$ & 3rd quartile & Min-max \\
\hline Number of procedures & 1 & 1 & 2 & $1-5$ \\
\hline Cumulative DAP $\left(\mathrm{Gy} . \mathrm{cm}^{2}\right)$ & 25 & 48 & 100 & $3-803$ \\
\hline Cumulative effective dose $(\mathrm{mSv})$ & 5 & 10 & 20 & $1-161$ \\
\hline Cumulative organ dose (mGy) & & & 79 & $2-540$ \\
\hline \multicolumn{1}{c}{ Lung } & 22 & 40 & 69 & $2-619$ \\
\hline \multicolumn{1}{c}{ Oesophagus } & 16 & 31 & 21 & $1-181$ \\
\hline \multicolumn{1}{c}{ Bone marrow } & 5 & 10 & 7 & $1-50$ \\
\hline \multicolumn{1}{c}{ Breast dose } & 2 & 3 & & \\
\hline DAP: Dose area product. & & &
\end{tabular}

DAP: Dose area product.

This is linked to a significant increased fluoroscopy DAP value for this category of examination when compared to CA. The median annual cumulative effective dose, DAP and organ doses per patient are reported in Table II. Only one patient received an effective dose greater than $100 \mathrm{mSv}$. The value of cumulative DAP was greater than $300 \mathrm{~Gy} . \mathrm{cm}^{2}$ for 49 patients ( $3 \%$ of the population). The individual cumulative absorbed doses received by organs surrounding the heart during one year are reported in Figure 1. Whatever the organ, a wide range of doses was observed. However, interquartile range remained quite small. Only $302(19 \%)$ patients received more than $100 \mathrm{mGy}$ to the lung, 237 (15\%) to the oesophagus and $15(1 \%)$ to the bone marrow. No patient received more than $50 \mathrm{mGy}$ to the breast.

The highest median dose values were found for the lung ( $41 \mathrm{mGy}$ ), an organ which is directly impacted by the primary X-ray beam during the procedure. The oesophagus's median dose value was found to be slightly lower (31 mGy), while the bone marrow (median dose of $10 \mathrm{mGy}$ ) and breast (median dose of $4 \mathrm{mGy}$ ) doses were much lower; these organs being less frequently exposed to high X-ray intensity due to their anatomical position and the X-ray detector side.

\section{Discussion}

This study provided a detailed assessment of clinical features and cumulative dosimetric data of an adult cohort population having undergone ICP over 1 year time. Regarding dosimetry, this study provided that cumulative absorbed doses received during ICP by the most exposed organs around the heart such as lungs, oesophagus, bone marrow and breasts could be relatively high with a wide range 

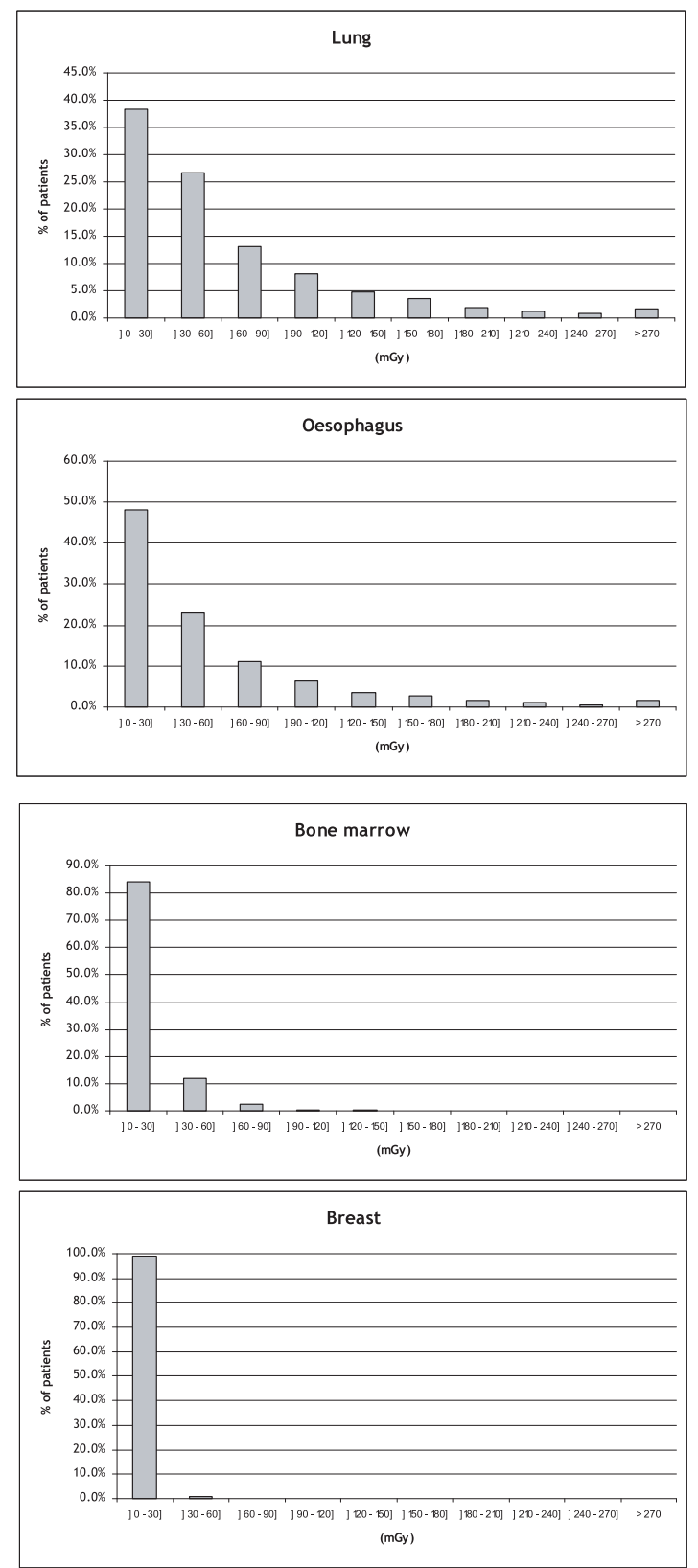

Figure 1 -Distribution of individual cumulative organ-doses (mGy) for the lung, oesophagus, bone marrow and breast. 
of doses - from $0.1 \mathrm{mGy}$ to several hundreds of $\mathrm{mGy}$ - even if the median effective dose remained at $10 \mathrm{mSv}$.

This study was conducted on a very large sample of patients with one year follow-up of their exposure. For all the patients, it was possible to calculate organ doses received during each procedure by some of the heart's neighbouring organs which are recognized as being rather radiosensitive (UNSCEAR, 2006) through a mathematical model. Organ doses are seldom considered in the field of IC (Pattee et al., 1993; Harrison et al., 1998; Delichas et al., 2003) or in other areas of medical exposure (Ruiz-Cruces et al., 2000) due to its difficult estimation. However, the absorbed dose to an organ represents a rather appropriate dosimetric indicator as compared to effective dose in order to evaluate a potential adverse effect of ionizing radiation to a specific organ. Indeed, the effective dose, usually used in IC as in other fields of medical exposure and radiological protection in both adult (Betsou et al., 1998; Harrison et al., 1998; Cusma et al., 1999; Katritsis et al., 2000; Efstathopoulos et al. 2004; Bogaert et al., 2008; Smith and Rivers, 2008; Bahreyni et al., 2008) and paediatric (Axelsson et al., 1999; Rassow et al., 2000) populations, reflects the health detriment to the whole body in case of a homogeneous exposure. But its relevance is less evident in cases of focused or heterogeneous exposure. The building of a mathematical model dedicated to this specific population of patients allowed us to better characterize organ doses than in previously reported studies (Pattee et al., 1993; Harrison et al., 1998; Delichas et al., 2003), taking into account operator effect and the type of procedure, both factors known to influence doses. The procedures were all performed using the same cathetherism room, reducing dose variability linked to the equipment. As found in other studies (Pattee et al., 1993; Betsou et al., 1998; Katritsis et al., 2000; Delichas et al. 2003; Efstathopoulos et al., 2004; Smith and Rivers, 2008), higher values of DAP were observed for PTCAs rather than for CAs in our study, due to the significantly increased fluoroscopy DAP values in the case of PTCA. As one might expect, the average organ dose values due to a CA or a PTCA were significantly higher than those currently observed for conventional radiology procedures, ranging from 2 to $436 \mathrm{mGy}$ for the lung while the dose associated to a CT scan is around $10 \mathrm{mGy}$ (UNSCEAR, 2006). Compared to others studies calculating organ doses the mean doses in our study were smaller than previously reported (Pattee et al., 1993; Delichas et al., 2003) except for one study (Harrison et al., 1998) considering only CA, which observed smaller lung doses than we did. Differences in the treated population, operator's skills, awareness of radiation protection rules and mathematical models used to calculate organ doses could explain some of these discrepancies. Yet we still observed that the most impacted organ, i.e. the lung, received a cumulative dose greater than $100 \mathrm{mGy}$ in $20 \%$ of 
the population even if the corresponding effective dose remained far below the doses for which potential health effects might be expected.

The estimation of the cumulative dose over the year for each patient allowed to better evaluate the cumulative exposure of this population to ionizing radiation linked to ICP, while the previous studies (Pattee et al., 1993; Harrison et al., 1998; Delichas et al., 2003) focusing on organ dose estimation did not take into account the fact that patients could be subjected to several ICP. Furthermore, one year of follow-up remained limited because of the chronic evolution of the disease. Additional CAs or PTCAs were likely to be performed on the same cohort in the following years. The dosimetry findings of this study therefore probably underestimate the actual cumulative dose received by these patients.

Despite clinical advantages and benefits of IC, the repeated use of X-rays during these procedures and the values of the observed cumulative doses raise the problem of the potential detriment to the patient due to such an exposure. It would require on one hand an optimization of the radiation protection during these procedures in order to deliver the lowest possible doses and on the other hand to set up surveillance of short and long term health effects for the population at risk.

With the aim of setting up an epidemiological study to examine the excess risk of radiation-induced cancers due to one or more ICP, this work has resulted in a better description of the clinical characteristics of the target population. The vast majority of the patients included in the study were males. About a quarter of the population was under 60 years old and the rate of co-morbidities was, as expected, higher in the cohort than in the general population (Ricordeau et al. 2000; Gourdy et al., 2001; Charles et al., 2002; Girerd et al., 2003). The number of smokers or former smokers - which concerned a third of our study population - was significantly higher than in the general population (Guilbert and Gauthier, 2006) (26\%) and rose to $64 \%$ and $50 \%$, respectively for men and women under 60 years old. All these co-morbidities and smoking habits could be associated with a lower survival rate for patients having undergone ICP than that of the general population matched for age and gender, as shown by a Dutch study (van Domburg et al., 2001). Therefore, this reduced life expectancy should be taken into account when determining the size of the sample population to be followed in an epidemiological study. Preliminary to a population size calculation, a specific risk assessment for cancer has to be carried out. Based on such detailed description of dosimetric data (absorbed organ doses) of an adult French population undergoing IC procedures and considering several scenarios of exposure, according to the latest radiation risk models (National Research Council and Committee on the Biological Effects of Ionizing Radiation, 2006), a life time excess risk of lung cancer linked to ICP will be developed in a future publication. 


\section{Conclusion}

This study has shown that the doses received by patients during ICP could be high, especially since these patients could be exposed several times according to the chronic evolution of the coronary disease. A careful radiation protection approach is needed for those patients in order to reduce their exposure to ionizing radiation. Health monitoring as well as long-term epidemiological studies of the most exposed patients undergoing ICP should help to assess the radiation-induced cancer risk of the radiosensitive organs around the heart, but need to take into account the clinical specificities of the target population.

Statement of conflict of interest: None of the authors reported a conflict of interest.

\section{REFERENCES}

Axelsson B., Khalil C., Lidegran M., Schuwert P., Mortensson W. (1999) Estimating the effective dose to children undergoing heart investigations - a phantom study, Br. J. Radiol. 72, 378-383.

Bahreyni Toossi M.T., Zare H., Bayani S., Esmaili S. (2008) Organ and effective doses of patients arising from coronary angiography and percutaneous transluminal coronary angioplasty at two hospitals in Mashhad-Iran, Radiat. Prot. Dosim. 128, 363-366.

Betsou S., Efstathopoulos E.P., Katritsis D., Faulkner K., Panayiotakis G. (1998) Patient radiation doses during cardiac catheterization procedures, Br. J. Radiol. 71, 634-639.

Bogaert E., Bacher K., Thierens H. (2008) A large-scale multicentre study in Belgium of dose area product values and effective doses in interventional cardiology using contemporary X-ray equipment, Radiat. Prot. Dosim. 128, 312-323.

Boice J.D. Jr., Morin M.M., Glass A.G., Friedman G.D., Stovall M., Hoover R.N, Fraumeni J.F. Jr. (1991) Diagnostic X-ray procedures and risk of leukemia, lymphoma, and multiple myeloma, Jama 265, 1290-1294.

Charles M.A., Basdevant A., Eschwege E. (2002) Prévalence de l'obésité de l'adulte en France : la situation en 2000, Ann. Endocrinol. (Paris) 63, 154-158.

Cusma J.T., Bell M.R., Wondrow M.A., Taubel J.P., Holmes D.R. Jr. (1999) Real-time measurement of radiation exposure to patients during diagnostic coronary angiography and percutaneous interventional procedures, J. Am. Coll. Cardiol. 33, 427-435.

Delichas M.G., Psarrakos K., Molyvda-Athanassopoulou E., Giannoglou G., Hatziioannou K., Papanastassiou E. (2003) Radiation doses to patients undergoing coronary angiography and percutaneous transluminal coronary angioplasty, Radiat. Prot. Dosim. 103, 149-154.

Doody M.M., Lonstein J.E., Stovall M., Hacker D.G., Luckyanov N., Land C.E. (2000) Breast cancer mortality following diagnostic X-rays: findings from the US Scoliosis cohort study, Spine 25, 2052-2063.

Efstathopoulos E.P., Karvouni E., Kottou S., Tzanalaridou E., Korovesis S., Giazitzoglou E., Katritsis D.G. (2004) Patient dosimetry during coronary interventions: a comprehensive analysis, Am. Heart J. 147, 468-475.

Faulkner K., Vano E. (2001) Deterministic effects in interventional radiology, Radiat. Prot. Dosim. 94, 95-98. 
Girerd X., Mourad J.J., Vaisse B., Poncelet P., Mallion J.M., Herpin D. (2003) Estimation du nombre des sujets traités pour une hypertension, un diabète ou une hyperlipidémie en France : étude FLAHS 2002, Arch. Mal. Coeur Vaiss. 96, 750-753.

Gourdy P., Ruidavets J.B., Ferrieres J., Ducimetiere P., Amouyel P., Arveiler D., Cottel D., Lamamy N., Bingham A., Hanaire-Broutin H. (2001) Prevalence of type 2 diabetes and impaired fasting glucose in the middle-aged population of three French regions - The MONICA study 1995-97, Diabetes Metab. 27, 347-358.

Guilbert P., Gauthier A. (2006) Baromètre Santé 2005, INPES.

Harrison D., Ricciardello M., Collins, L. (1998) Evaluation of radiation dose and risk to the patient from coronary angiography, Aust. N. Z. J. Med. 28, 597-603.

Howe G.R. (1995) Lung cancer mortality between 1950 and 1987 after exposure to fractionated moderate-dose-rate ionizing radiation in the Canadian fluoroscopy cohort study and a comparison with lung cancer mortality in the Atomic Bomb survivors study, Radiat. Res. 142, 295-304.

Infante-Rivard C., Mathonnet G., Sinnett D. (2000) Risk of childhood leukemia associated with diagnostic irradiation and polymorphisms in DNA repair genes, Environ. Health Persp. 108, 495-498.

Journy N., Sinno-Tellier S., Maccia C., Le Tertre A., Eilstein D., Pagès P., Pirard P., Donadieu J., Bar O. (2011) Main clinical, therapeutic and technical factors related to patient's maximum skin dose in interventional cardiology procedures, Br. J. Radiol., in press.

Katritsis D., Efstathopoulos E., Betsou S., Korovesis S., Faulkner K., Panayiotakis G., Webb-Peploe M.M. (2000) Radiation exposure of patients and coronary arteries in the stent era: A prospective study, Catheter Cardiovasc. Interv. 51, 259-264.

Lambe M., Hall P., Granath F., Sadr Azodi O., Nilsson T. (2005) Coronary angioplasty and cancer risk: a population-based cohort study in Sweden, Cardiovasc. Intervent. Radiol. 28, 36-38.

Le Tourneau T., Blanchard D., Lablanche J.M., Monassier J.P., Morice M.C., Cribier A., Meier P., Puel J. (2002) Évolution de la cardiologie interventionnelle en France au cours de la dernière décennie (1991-2000), Arch. Mal. Coeur Vaiss. 95, 1188-1194.

Malisan M.R., Padovani R., Faulkner K., Malone J.F., Vano E., Jankowski J., Kosunen A. (2008) Proposal for a patient database on cardiac interventional exposures for epidemiological studies, Radiat. Prot. Dosim. 129, 96-99.

McLaughlin J.R., Kreiger N., Sloan M.P., Benson L.N., Hilditch S., Clarke E.A. (1993) An historical cohort study of cardiac catheterization during childhood and the risk of cancer, Int. J. Epidemiol. 22, 584-591.

Meinert R., Kaletsch U., Kaatsch P., Schuz J., Michaelis J. (1999) Associations between childhood cancer and ionizing radiation: results of a population-based case-control study in Germany, Cancer Epidemiol. Biomarkers Prev. 8, 793-799.

Modan B., Keinan L., Blumstein T., Sadetzki S. (2000) Cancer following cardiac catheterization in childhood, Int. J. Epidemiol. 29, 424-428.

National Research Council of the National Academies (2006) Commitee to assess Health Risks from Exposure to Low Levels of Ionizing Radiations; Nuclear and Radiation Studies Board, Division on Earth and Life Studies, Health Risks From Exposure to Low Levels of Ionizing Radiations: BEIRVII Phase 2, 2006, Washington DC: The National Academies Press.

Pattee P.L., Johns P.C., Chambers R.J. (1993) Radiation risk to patients from percutaneous transluminal coronary angioplasty, J. Am. Coll. Cardiol. 22, 1044-1051.

Preston D.L., Ron E., Tokuoka S., Funamoto S., Nishi N., Soda M., Mabuchi K., Kodama K. (2007) Solid cancer incidence in atomic bomb survivors: 1958-1998, Radiat. Res. 168, 1-64.

Preston D.L., Shimizu Y., Pierce D.A., Suyama A., Mabuchi K. (2003) Studies of mortality of atomic bomb survivors. Report 13: Solid cancer and noncancer disease mortality: 1950-1997, Radiat. Res. 160, 381-407. 


\section{PATIENT CUMULATIVE RADIATION EXPOSURE IN INTERVENTIONAL CARDIOLOGY}

Rassow J., Schmaltz A.A., Hentrich F., Streffer C. (2000) Effective doses to patients from paediatric cardiac catheterization, Br. J. Radiol. 73, 172-183.

Ricordeau P., Weill A., Vallier N., Bourrel R., Fender P., Allemand H. (2000) L'épidémiologie du diabète en France métropolitaine. Diabetes Metab. 26, Suppl 6, 11-24.

Ruiz-Cruces R., Perez-Martinez M., Tort Ausina I., Munoz V., Martinez-Morillo M., Diez de los Rios A. (2000) Organ doses, detriment and genetic risk from interventional vascular procedures in Malaga (Spain), Eur. J. Radiol. 33, 14-23.

Smith I.R., Rivers J.T. (2008) Measures of radiation exposure in cardiac imaging and the impact of case complexity, Heart Lung. Circ. 17, 224-231.

Tapiovaara M., Lakkisto M., Seromaa, A. (1997) PCXMC, a PC-based Monte Carlo program for calculating patient doses in medical x-ray examinations, Stuk-A139.

UNSCEAR (2006) United Nations Scientific Committee on the Effects of Atomic Radiation, Health Phys. 79, 314.

van Domburg R.T., Foley D.P., de Feyter P.J., van der Giessen W., van den Brand M.J., Serruys P.W. (2001) Long-term clinical outcome after coronary balloon angioplasty: identification of a population at low risk of recurrent events during 17 years of follow-up, Eur. Heart J. 22, 934941.

Vano E., Goicolea J., Galvan C., Gonzalez L., Meiggs L., Ten J.I., Macaya C. (2001) Skin radiation injuries in patients following repeated coronary angioplasty procedures, Br. J. Radiol. 74, 10231031. 